\title{
Can Systems Dynamics be effective in modelling dynamic business systems?
}

\author{
Amir M. Sharif ${ }^{1}$ \\ Information Systems Evaluation and Integration Group (ISEing) \\ School of Information Systems, Computing and Mathematics, \\ Brunel University, \\ Uxbridge, UB8 3PH
}

The economist and statistician George P.E. Box, with reference to statistical probability models, notably opined that "All models are wrong - but some models are useful" (Box, 1979). This largely misquoted but nonetheless famous statement, outlined Box's view that decision makers sometimes have to make decisions with incomplete information, which may be only explained by the best available models. As such, any mental or conceptual model which attempts to encapsulate all possible facets of a given system or situation, may be limited in its expression due to realworld complexity or due to subjective over-simplification of the same reality, at the time that the model was formulated. Box's argument is that if the boundaries of a system can be defined as far as possible, then the resulting systems model, can also be restricted to be within realistic and quantifiable bounds.

Achieving accuracy within a representation of the real world in this way, becomes increasingly difficult, as the level of complexity of the model increases to accommodate an ever finer granularity of representation. Sterman suggests that any model of the real world should yield a fundamental kernel of knowledge at its core, about the context within which it exists. But at the same time, this model should allow us to understand its imperfections and the limitations of the world it is trying to represent, through the inclusion of human, social, systemic and process flows and other impinging factors (Sterman, 2002). Indeed the inclusion and use of human expert knowledge is the fulcrum upon which such representations pivot (Ford and Sterman, 1998).

A natural consequence of this approach, means that if better, detailed or more complex representations of reality are defined, the accuracy of our predictions and quality of decisions should also increase. Any and every technique which can help BPM and MIS researchers, as well as industry practitioners, to uncover and relate tangible and intangible factors, should therefore be pursued. At the junction of the disciplines of management, social, behavioural, political, and more recently, information sciences, the field of Systems Dynamics aims to provide the researcher with such a tool to resolve these questions. Systems Dynamics (or Systems Thinking as it is otherwise known) has existed in the academic as well as industrial R\&D community for over 25 years at least (Ackoff, 1974; Bertalanffy, 1976), and has grown to become a standard modelling technique in the armoury of the inquisitive in

\footnotetext{
${ }^{1}$ Visiting Research Fellow, email: ams@amir.demon.co.uk
} 
that time. The methods and approaches that can be employed range from variations on flow charting and state transition and dependency diagrams; through to 'bounding box' models (which model fixed and semi-fixed imaginary boundaries around a system); so-called 'rich picture' diagrams (characterised by the 'Weltanschauung' world view - of Checkland's Soft Systems Methodology - see Checkland, 1981); and more fundamentally, system archetypes (which ultimately define systems which have pre-defined behaviour and outcomes - see Ackoff, 1974 and Kim, 1995). The question that I pose is whether or not such systems dynamics approaches allow and provide an answer to Box's enigma of generating 'complete' models of the world around us. To begin to answer this, I choose to view those systems which are of interest to readers of this journal, namely business process and information management systems. The only question to be asked perhaps, is to what level of detail and accuracy do such systems need to be modelled in order for those representations to be realistic? And it is precisely this question that I believe can help us determine whether or not systems dynamics is useful and appropriate for modelling dynamic business systems.

The answer I suspect, that most if not all BPM and MIS researchers will provide is 'any level of detail and accuracy will be sufficient as long as it is a representation that can be used as a vehicle for communication and disseminating knowledge and understanding about the business system being analysed'. Zachman and Sowa (1992) take this view too in part, in terms of modelling enterprise IT/IS architecture for example. This is a valid and entirely sensible and rational answer, and one which I myself, wholeheartedly concur and agree with. For example, I could conceivably model a steel production facility, as a series of process flows, or as a number of engineering decision steps - or even as a visual 'mind map' of those dependencies and interactions connected with the smelting, rolling, stamping, quality assurance and delivery processes. However, this approach to using and applying a seemingly endless list of modelling tools (including proprietary, theoretical as well as heuristic and empirical models), is prone to bias and validity risk overall, in my view for two reasons.

Firstly, because of the flexibility and simplicity with which such tools can be applied to modelling a system, it is quite possible to apply the wrong method to a given case; and thereby reach the wrong conclusions about the behaviour of that system. How would you know you were wrong though? The answer to this belies the second reason. This is that modelling a system can easily be done at the wrong time also, and for the wrong reasons with the wrong tools. (Incidentally when I state the word 'wrong' I do not necessarily mean incorrect, but rather mean inappropriate.) Thus, the intent must match the purpose, be it to represent, predict, monitor, optimise, or carry out a post-hoc evaluation of a dynamic system. So, in effect choosing a modelling methodology and tools is reliant upon choosing which tool to use and when to use it appropriately. This may seem an obvious statement, and in many ways it is - and leads me onto a key solution to both of these questions raised and also Box's statement (so 'here comes the science bit'). Representing business and IT/IS systems using systems dynamics / thinking tools and concepts can only be effective if such approaches are understood, learnt, employed and disseminated by the industrial practitioner community (to give some context and application to real world situations); and are also taught as a fundamental part of BPM and MIS syllabi in universities and colleges also. I feel that systems dynamics as a field has great 
potential to be used more fervently within the business process community, and it is only being limited by a lack of understanding and knowledge about it presently, in my opinion. Those researchers and practitioners who consider themselves to be empirical purists, tend to shun systems dynamics / thinking as they view the inherent formalism involved in some of the methods to be leaning towards being more quantitative, and thus restrictive to modelling those 'soft' human issues. I too, held this view until I decided only recently to delve into this field in more detail.

As such, and in the light of previous research efforts in terms of (fuzzy) cognitive mapping techniques (Kosko, 1991; Mentazemi and Conrath, 1986), I was particularly drawn to the concepts of system archetypes (Ackoff, 1974) and morphological analysis (Zwicky, 1969). Whilst archetypes have their basis in 'hard' systems theory (Bertalanffy, 1950), some would argue that morphological analysis is not strictly a systems method at all, being more closely aligned with forecasting and strategic planning approaches - however, I beg to differ on that). I was surprised to learn that these techniques have been used so very sparingly over the years, and in terms of the BPM and MIS community, have rarely been used if at all. Upon reading and comparing these techniques to those that I know and use frequently, it struck me just how flexible and amenable both of these techniques may be. In any case, I began to see the benefits that each approach had in viewing and modelling the IS evaluation process, for example. I was able to see how the investment appraisal decision-making process could potentially be viewed in terms of basic systems archetypes such as 'Fixes that Fail', 'Eroding Goals', 'Attractiveness Principle', and 'Tragedy of the Commons'. Similarly by using morphological analysis, I could at once detail and define all possible known variables of the ISE process and step through numerous (and perhaps albeit, fanciful) combinations and outcomes, of different technology management and investment scenarios (as outlined by Ritchey, 1997).

So I believe that there is a strong case for starting to apply systems dynamics methods more openly in the BPM and MIS research fields, as I feel the tools and techniques available are vastly under-rated in terms of their applicability and capability to provide novel representations of real world situations. Because these techniques may not be understood or even taught sufficiently well, I also think their use as complementary methods to other forms of modelling (such as cognitive mapping, strategic planning etc), is also non-existent. However, the use of such methods could yield significant and interesting results within the given research communities (although I have yet to find or see research which supports or employs this approach). By increasing and improving upon our experiences in modelling real world situations in this way, maybe we can one day falsify Box's epithet and stand to claim: 'All models are wrong, but system dynamics models tend to be the most useful'.

\section{Amir M. Sharif}

\section{Disclaimer}

The author wishes to assert that the views and opinions expressed in this article are solely those of the author. 


\section{References}

Ackoff, R.L. (1974). Redesigning the Future: A Systems Approach to Societal Problems. New York : John Wiley and Sons.

Axelrod, R. (1976). Structure of Decision: the cognitive maps of political elites, Princeton University Press.

Bertalanffy, L. (1950). An outline of General Systems Theory, British Journal for the Philosophy of Science, 1 : 139 - 164

Bertalanffy, L. (1976). General Systems Theory. George Braziller, New York.

Box, G.E.P. (1979). Robustness in the Strategy of Scientific Model building. In (Eds. R.L. Launer and G. N. Wilkinson). Robustness in Statistics. New York : NY, Academic Press, pp. 202.

Checkland, P. (1981). Systems Thinking, Systems Practice. London, John Wiley \& Sons.

Daniel K. (1995). Archetypes as Dynamic Theories. The Systems Thinker, June/July, 1995.

Ford, D.N., and, Sterman. J. D. (1998) Expert knowledge elicitation to improve mental and formal models, System Dynamics Review, 14 (4) : 309 - 340.

Fowler, M., and Scott, K. (1998). UML Distilled - Applying the Standard Object Modelling Language. Addison Wesley Longman Inc..

Kosko, B. (1991). Neural Networks and Fuzzy Systems, Prentice-Hall, Inc., Upper Saddle River, NJ, USA.

Mentazemi, A., and Conrath, D. (1986). The use of cognitive mapping for information requirement analysis. Management Information Systems Quarterly, March 1986, pp.45 - 56.

Ritchey, T. (1997). Scenario Development and Risk Management using Morphological Field Analysis. Proceedings of the 5th European Conference on Information Systems, Cork, Cork Publishing Company, pp. 1053 - 1059.

Sterman, J.D. (2002). Reflections on becoming a systems scientist. Systems Dynamics Review, 19 (4) : $501-531$.

Zachman, J.A., and Sowa, J.F. (1992). Extending and Formalizing the Framework for Information Systems Architecture, IBM Systems Journal. 31 (3): 590 - 616.

Zwicky, F. (1969). Discovery, Invention, Research - Through the Morphological Approach. The Macmillan Company, Toronto. 